\title{
Nanoimprint lithography - the past, the present and the future
}

\author{
Dongxu $\mathrm{Wu}^{1,2}$, Nitul S Rajput ${ }^{2}$ and Xichun $\mathrm{Luo}^{2, *}$
}

1. Centre for Precision Engineering, School of Mechatronics Engineering, Harbin Institute of Technology, Harbin 15001, P. R. China.

2. Centre for Precision Manufacturing, Department of Design, Manufacture and Engineering Management, University of Strathclyde, 75 Montrose Street, Glasgow G1 1XJ, UK.

Corresponding author: Prof. Xichun Luo, e-mail: xichun.luo@strath.ac.uk; Tel: +44 141574 5280

\begin{abstract}
Nanoimprinting lithography technique uses a very simple concept of transferring pattern of nanoscale features from a mold to a target substrate. In the past two decades, this technique has successfully broken through the barrier of laboratory scale production and become an industrial scale production technique. This article reviews major types of nanoimprint lithography techniques which are mainly base on thermal treatment, ultraviolet light exposure, laser light irradiation or electro chemical reaction. The machining mechanism and components of major nanoimprinting methods are described. A technical comparison of these methods is presented through the analysis of their state-of-the-art research advances. Moreover, the advanced applications of nanoimprint lithography in the fields of optoelectronic devices, solar cells, memory devices, nanoscale sensors and biology are presented. Finally, the article investigates the challenges faced by nanoimprint lithography and its future trend, and discusses the possible solutions to meet these challenges.
\end{abstract}

Keywords: nanofabrication, nanoimprint lithography, throughput, resolution, roll-to-roll

\section{Introduction}

Currently, the research on high throughput, high precision and low cost fabrication approach for nanostructures has attracted a lot of attentions in the field of nanoscience and nanotechnology. Such fabrication technique is of crucial importance for the widespread and 
commercialisation of nanotechnology as nanostructures are the key building blocks and driving forces for microchips, microelectronic devices, biosensors and high density magnetic storage media [1-5] to reach their ultimate capacities. As such the integration density of the semiconductor devices and circuitry is continuously growing, the dynamic random-access memories (DRAMs) and microprocessors are experiencing a steady growth by $50 \%$ and $35 \%$ per year [6].

In early 1990's, scanning probe microscope (SPM) lithography [7, 8] were proposed to fabricate nanostructures. Even with further technical improvements [9], SPM lithography still suffers from low throughput and is therefore only applicable in a laboratory scale. On the other hand traditional high throughput optical lithography approaches such as, X-ray lithography and extreme ultraviolet (EUV) lithography are limited by the requirement of expensive equipment and mask, as well as the attainable resolution [10] due to Abbe diffraction limit. The breakthrough in mass production of nanostructures was made by Prof. Chou who proposed a nanofabrication technique, named as nanoimprint lithography (NIL) in 1995-1996 at NanoStructure Laboratory [11], University of Minnesota, USA. Since then NIL has evolved quickly to become one of the most promising nanopatterning processes and is considered as the future of nanofabrication.

Similar to other step and stamp approaches, the principle of NIL is to transfer the patterns of a given sample (such as mold) to a target substrate. This can be achieved by using mechanical contact, or heating, or curing [12], or by electrochemical reaction. NIL is a fast and low cost production process. With the help of modern NIL techniques, pattern of sub-5 $\mathrm{nm}$ resolution can be easily achieved [13]. NIL has some key advantages over other existing lithographic processes [14-16] which are summarized as follows:

- NIL is a cost-effective fabrication technique which is essential for commercial production. 
- NIL can provide high resolution structures. The resolution of a fabricated pattern is limited by the mold only.

- NIL is a fast process and NIL can be used to fabricate nanopatterns at a large scale in a short time.

Due to these advantages manufactures of hard disk drive and semiconductors find NIL as the most convenient production process. NIL has also been widely used in the fabrication of nanostructures for light emitting devices, memory devices, solar cell, flat panel display, and plasmonic devices, etc [17-20]. Because of its high-resolution dense pattern capability, NIL is also considered as the enabling fabrication technique for future flash based memory devices [16]. The conventional nanoimprint techniques are facing many challenges due to some imperfections. Firstly, the throughput of current approaches should be further improved to meet the dynamic market demand for commercial production. Moreover, even if the desired patterns have very small variation, the molds used in physical nanoimprint must be remanufactured by using reactive ion etching (RIE) [9] or electron beam lithography (EBL) [21]. Thirdly, the adhesion between mold and resist is a significant problem, because the mold and patterns may be broken during the procedure of mold release. This review article briefly walks through the history of imprinting process, and then discusses the major techniques developed for NIL and their applications. Finally, it gives a detailed discussion on the challenges and the future aspects of the nanoimprint lithography technique.

The article is segregated into the following sections and subsections:

- History of imprinting process

- Major NIL techniques developed

- Thermal NIL

- Ultraviolet (UV) NIL

- Laser-assisted direct imprint(LADI) 
- Nanoelectrode lithography

- Application of NIL

- Challenges and the future of NIL

\section{History of imprinting process}

Even though the term "nanoimprint lithography" is new, the concept of imprinting to replicate structure is old. Casting is a manufacturing process where a liquid is poured into a mold and subsequently allowed to solidify it. It has been one of the most popular manufacturing processes estimated to be used by the human civilizations since $6000 \mathrm{BC}$. The process of inserting a mold into a plastic material to replicate structure has been used by the old civilizations. This process is generally termed as embossing process and has been used to replicate and produce coins. It was also used for letterpress. Later the process of hot embossing was added to create structures on polymer materials [22, 23], ultra-thin teflon-like films [24], DNA separation and detection [25] and micro lens array [26].

The realization of creating nanostructures at a large scale using imprinting process came from Prof. Chou's work in 1995-1996 [10, 27]. He showed that nanostructures of $25 \mathrm{~nm}$ resolution could be achieved using imprinting processes. As shown in the schematic picture (Fig.1), a mold with feature size of few tens $\mathrm{nm}$ is used to press on a thermoplastic material substrate which is heated up during the molding process. If the temperature of the material increases above its glass transition temperature, the polymer will behave as a viscous material which helps the molding process. With subsequent RIE, the thickness contrast of the imprinted patterns can be transferred through the entire resist region. In the article published by Chou's group, a silicon dioxide mold was used. The patterns, which had a feature size of $25 \mathrm{~nm}$, were created using EBL technique. Polymethyl methacrylate (PMMA) layer of thickness 50-200 $\mathrm{nm}$ was prepared on a Si substrate in order to replicate the pattern [10]. The prepared PMMA layer must have the property of desired mold release (should not adhere to the mold after the 
release of the mold). After the imprinting, RIE was used to etch away the thin resist layers on the compressed portions to achieve a high quality pattern as shown in Fig. 2.Using this approach, patterns of different shapes of nanometre feature size were created (Fig. 3).

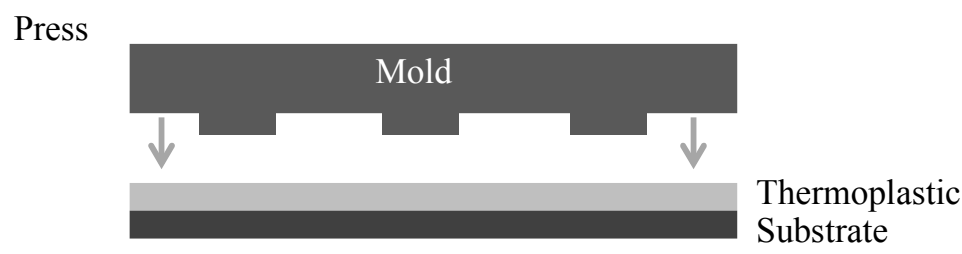

Remove

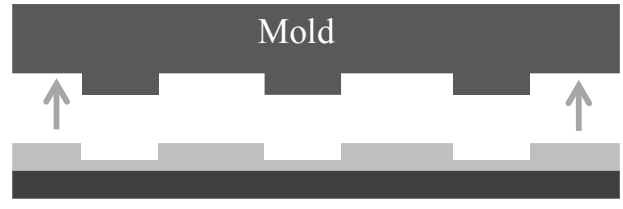

RIE

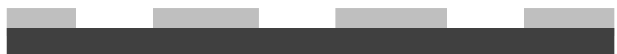

Fig.1 Schematic of the imprinting approach implemented by Prof. Chou [27]

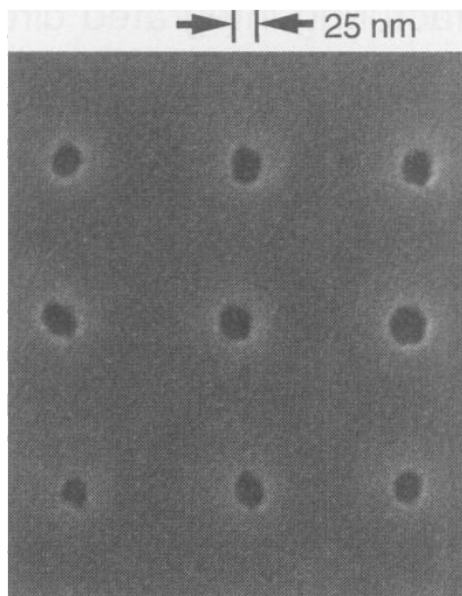

(a)

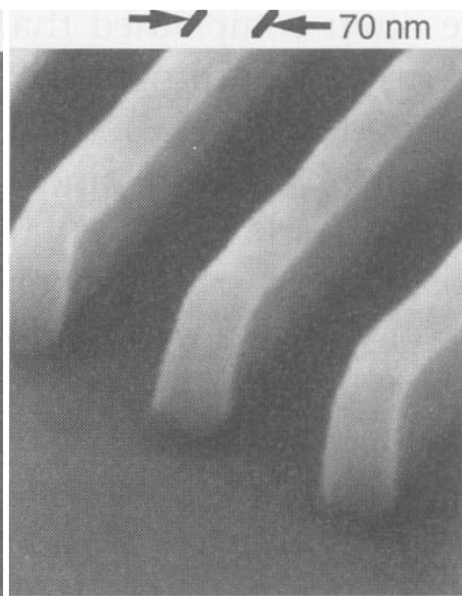

(b)

Fig.2 Scanning electron microscopy image of a (a) PMMA film having $25 \mathrm{~nm}$ hole structure (top view), (b) strip pattern formed on a PMMA film using the imprinting process (perspective view) [10] (Reprinted from ref. [10] with permission)

Using this flat imprint lithography technique, fabrication of nanostructures at a large-scale has been successfully demonstrated. Prof. Chou's group subsequently has introduced the concept of roller imprint lithography in 1998, a continuous nanoimprinting process [28].Two types of approaches have been discussed for roller imprint lithography in his paper, which are 
cylindrical mold method and flat mold method. As shown in Fig.3, in the cylindrical mold method, the mold is prepared on the surface of a cylindrical roller. In the second method, a flat mold of Si is placed on the substrate and a smooth roller is rotated over the flat mold.
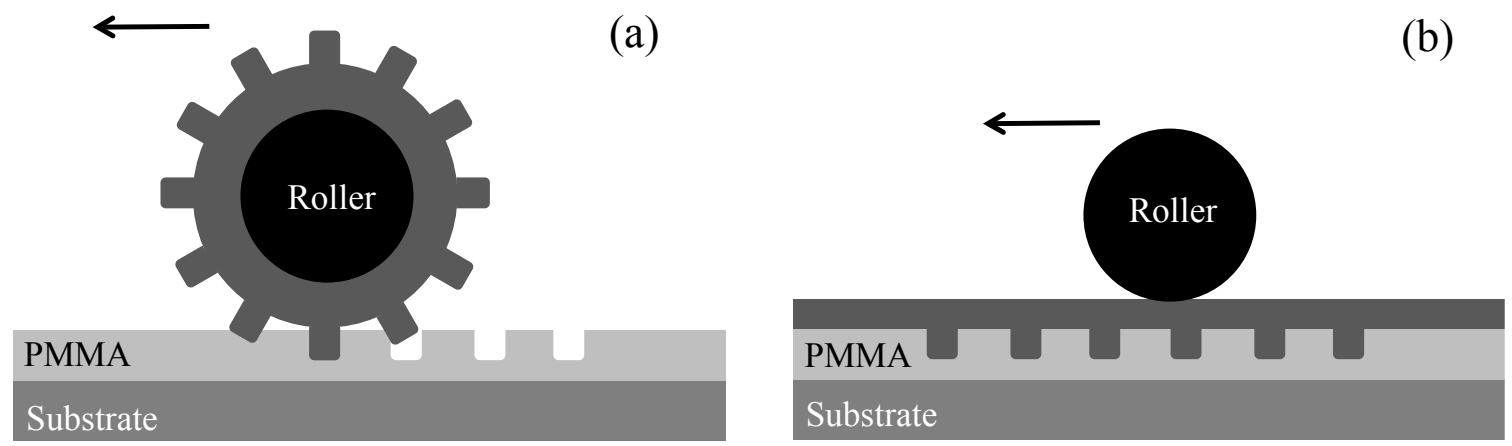

Fig.3 Schematic picture showing the roller NIL methods as perceived: (a) cylindrical mold method and (b) flat mold method [28]

In roller imprinting process, the temperature of the roller is kept above the glass transition temperature of the resist and the temperature of the resist is kept below its glass transition temperature. This ensures that only the contact region between the mold and the resist is suitable for the imprinting process. Using the first generation of roller NIL, resolution of sub$100 \mathrm{~nm}$ was achieved which was shown in Fig.4 [28].
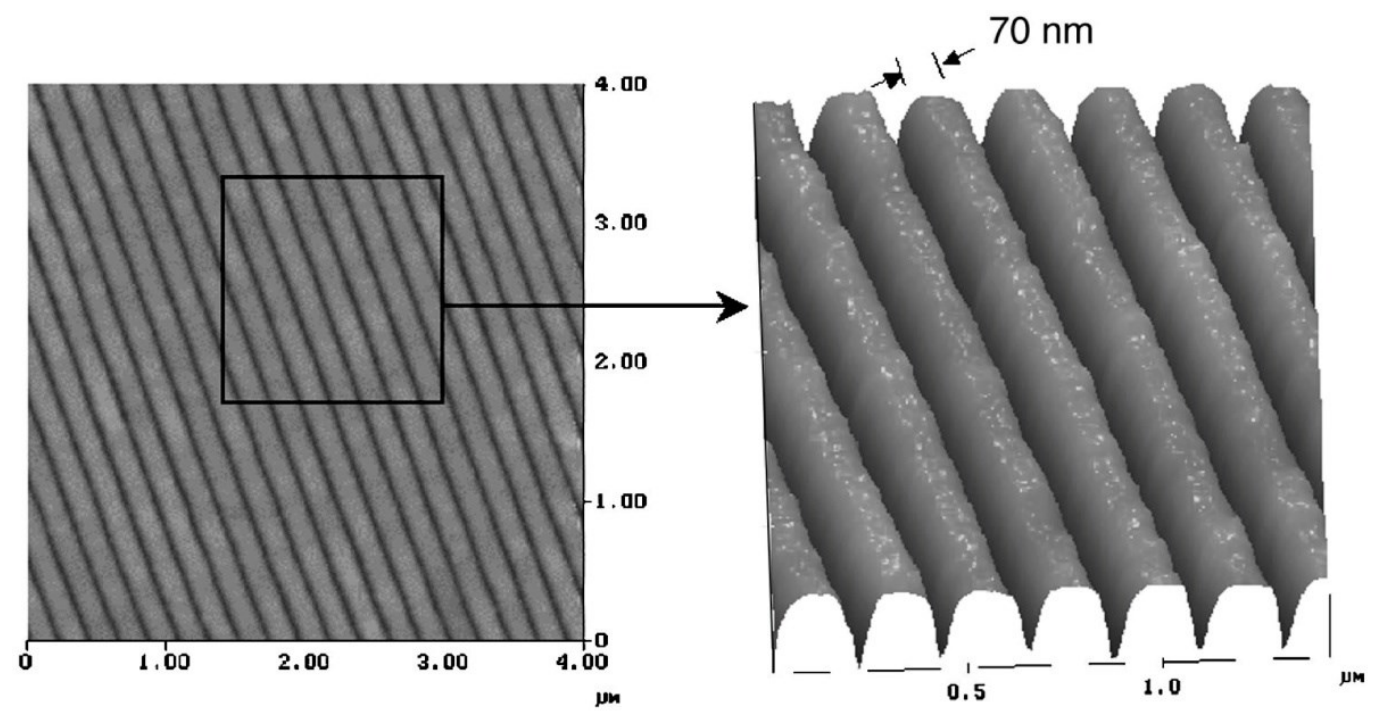

Fig.4 PMMA nanostructure of sub-100 nm resolution created using roller imprint method [28] (Reprinted from ref. [28] with permission) 


\section{Major NIL techniques developed}

Since the birth of NIL process two decades back, several research groups have contributed in developing several nanoimprinting methods and NIL has grown rapidly within a short time. Depending on the process used for nanoimprinting, major NIL techniques can be classified into four categories, which are discussed below.

\subsection{Thermal NIL}

\subsubsection{Machining mechanism of thermal NIL}

In order to print a pattern on the target sample using NIL process, the target material must be softened to take the pattern. One of the ways to achieve this condition is to heat the sample surface layer above the glass transition temperature $\left(T_{g}\right)$ of the material. Achieving the required temperature through heating can be approached through different ways. The resist can be directly heated up as discussed by Chou [10]. The resist is heated up above the $T_{g}$ and then the mold is pressed against the resist layer in order to imprint. Subsequently, the sample is cooled down and the mold is separated from the target sample. In order to achieve proper imprinting, the temperature and the pressure on the mold, and the time duration for holding the mold on the surface have to be controlled properly.

Instead of heating the sample, the mold can also be heated up. During the imprinting process, the mold touches the sample surface and only the contact region of the sample is getting sufficient temperature. In general, the molding temperature $\left(T_{m}\right)$ is kept above the glass transition temperature $\left(T_{g}\right)$ and the de-molding temperature $\left(T_{d m}\right)$ is kept below $T_{g}$. The local pressure on the sample has to be varied accordingly. In case of thermal roller NIL, the heating and the cooling procedure may become tricky.

\subsubsection{Components of Thermal NIL}

A typical thermal NIL system includes the following components:

- A plate or roller mold with nanopatterns; 
- A feeding and de-molding system;

- A heater is integrated with platform or roller installed on the moving stage to heat up the substrate or roller;

- The roller is also adapted to enhance the press force between the stamp and the substrate;

- In order to achieve proper heating and imprinting, the precise control system of pressure, temperature and cooling is needed;

- Substrate such as polymer.

\subsubsection{Advances in thermal NIL}

Hirai et al. [29] have studied the fracture defect of the polymer in thermal nanoimprint lithography. They concluded that the stress concentration at the corner of the pattern is the reason to induce the fracture defect. The strain is caused by the applied pressure below the glass transition temperature and the difference of the thermal expansion coefficients between the mold and the substrate. Bilenberg et al. [30] have established the Topas-based lab-on-achip (LOC) microsystems by using the thermal nanoimprint lithography and analysed the effect of the environmental stress cracking. In order to achieve highly efficient optoelectronic devices, the thermal nanoimprint lithography has been used to develop a direct indium tin oxide (ITO) nanopatterning technique to improve the transmittance and conductivity of the TCO layers [31]. Youn et al. [32] described a thermal roller NIL approach in their article. The schematic picture (Fig.5) shows the major components of the system developed by Youn et al. The stamp is connected with two moveable springs through the pullers. 


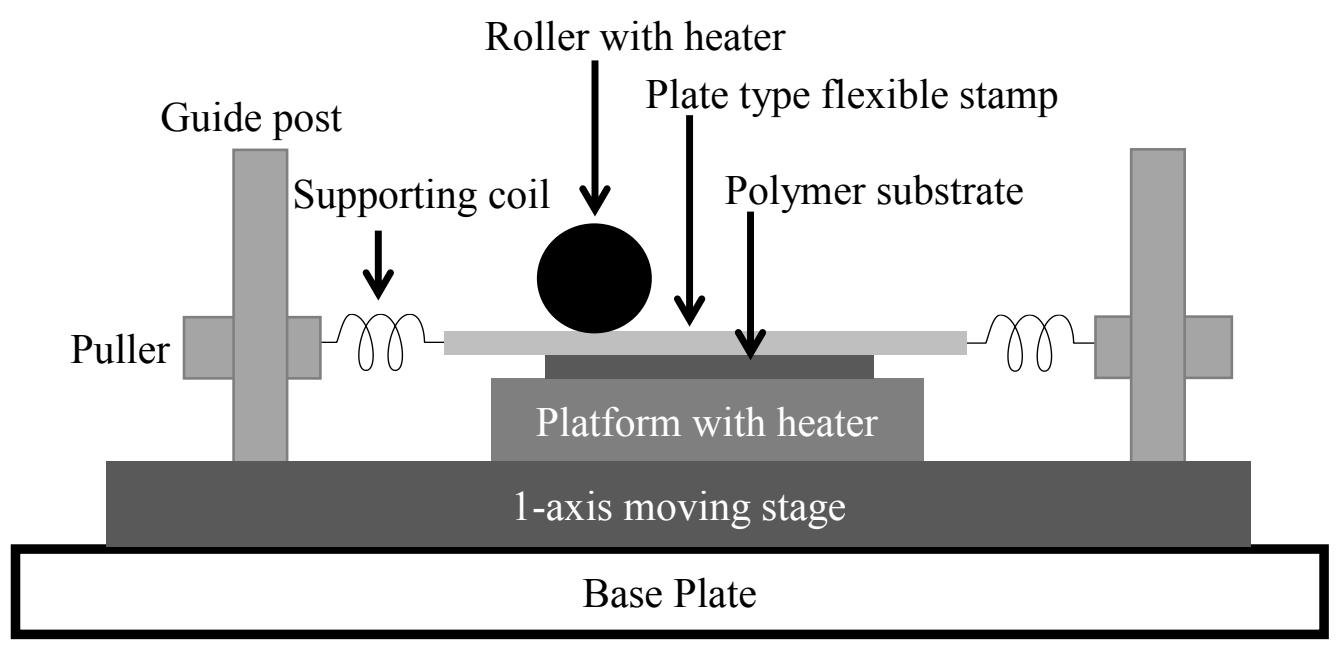

Fig.5 Schematic picture showing the thermal roller NIL approach [32]

The flow chart of the thermal roller NIL technique is described schematically in Fig.6. The stamp, which is supported by the coils, is pushed down to touch the polymer. The roller temperature is set above the $T_{g}$ and the temperature of the platform is set below the $T_{g}$. The stamp receives the heat from the roller. The roller is rolled over the stamp and as soon as the stamp touches the polymer with pressure, the imprinting process starts. Following this, the stage holding the polymer is moved parallel as shown in the schematic picture. The technique of thermal roller imprinting process developed in this way shows good results in replicating ultra precision micron scale structures at the scan speed of $0.1-10 \mathrm{~mm} / \mathrm{s}$ [32]. 

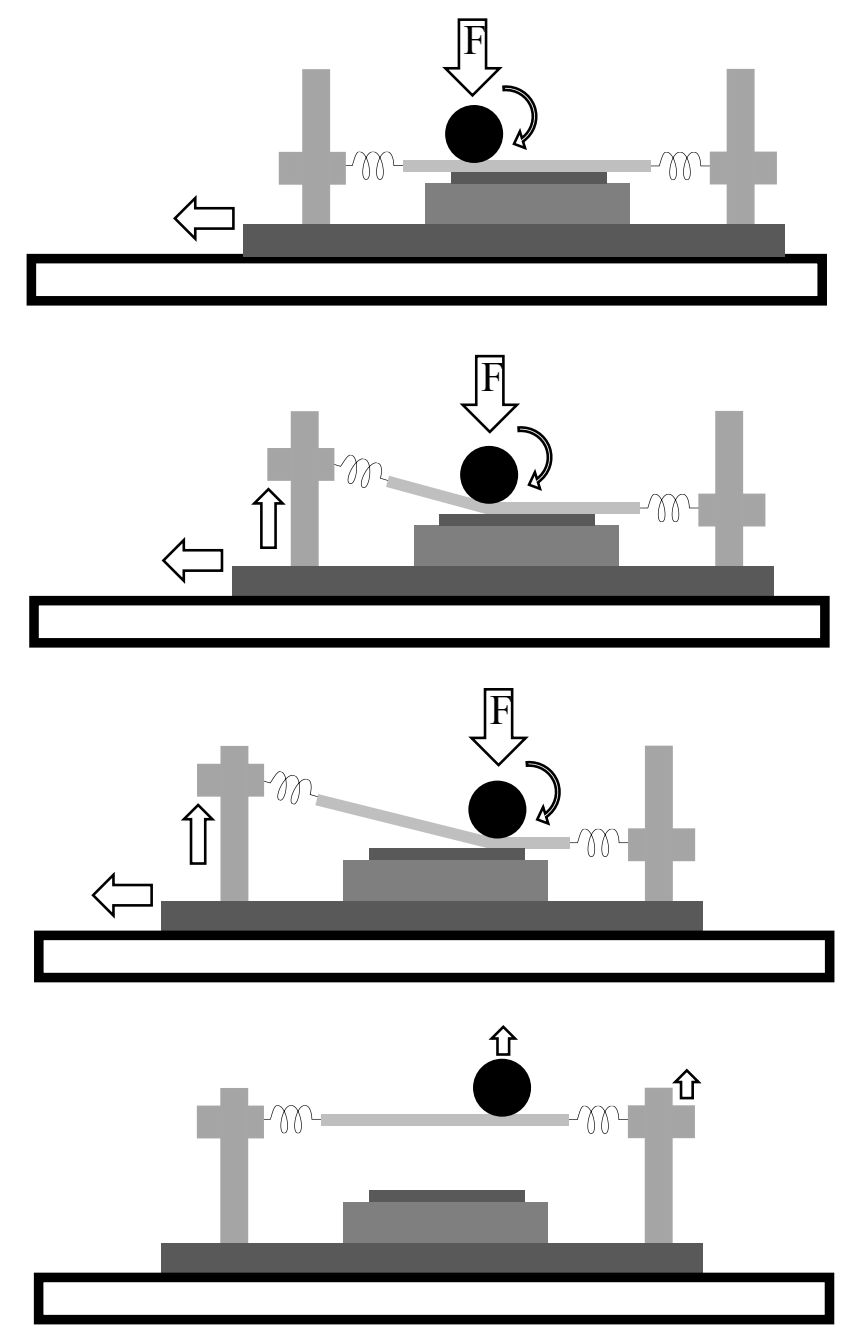

Fig.6 The schematic drawings of the steps in the thermal roller NIL process [32].

In thermal NIL, the mold surface should be hard enough and have the ability to avoid any distortion, even if it withstands the mechanical contact at high temperature and high pressure during the molding and demolding process. Hence, some hard materials such as $\mathrm{Si}$, fused silica, $\mathrm{SiC}$ and diamond can be chosen as the mold material used in thermal NIL. Meanwhile, the thermal expansion coefficient of the mold, polymer and substrate is a significant factor which can cause some defects such as distortion and asymmetric structure, especially when the difference of the thermal expansion coefficient is large. Also the demolding process has to be well-controlled in order to avoid the generation of distortion or damages on the imprinted structures. In addition, the effect of adhesion, friction, shrinkage and trapping 
which can happen between the surface of the mold and the imprinted structure has to be eliminated or controlled in a small scale [12].

\subsection{Ultraviolet (UV) NIL}

\subsubsection{Machining mechanism of UV NIL}

UV light has been used for a long time to create micro/nanostructures on photoresist material. The resist material is exposed to the UV light and chemical reaction is initiated. Subsequently, the sample is developed to extract the patterns. This technique can be used to develop patterns in a batch process.

Ahn et al. has developed a system to integrate UV lithographic capability with a roll nanoimprinting system [33]. The schematic picture of the continuous UV roll NIL system is shown in Fig.7. As shown in the figure, there is a dispensing unit to supply UV-curable polymer material on a transparent substrate, a UV illumination unit to process the pattern formation and a stamp roller unit. As the polymer-coated substrate passes through the roller stamp, the UV light is illuminated on the curing region and in this way patterns are generated. Fig.7(a) shows the design to work on a flat substrate, whilst further modified to work on flexible substrate is shown in Fig.7(b). Using the UV roll NIL technique, nanopatterns of 500 $\mathrm{nm}$ line structure and $50 \mathrm{~nm}$ pillar structure have been successfully fabricated [33].

\subsubsection{Components of $U V N I L$}

A typical UV NIL system includes the following components:

- A dispensing unit is needed to coat the UV-curable resin onto the substrate;

- A roller stamp with micro- or nanopatterns;

- In order to control the thickness of the final replica, a contact roller is adapted to control the pressure between the roller stamp and substrate;

- Rotating control system of roller and feeding system of substrate;

- The rigid or flexible substrate such as Si or polyester; 
- UV-curable resin;

- A UV light illumination unit is needed to cure the UV-curable resin.

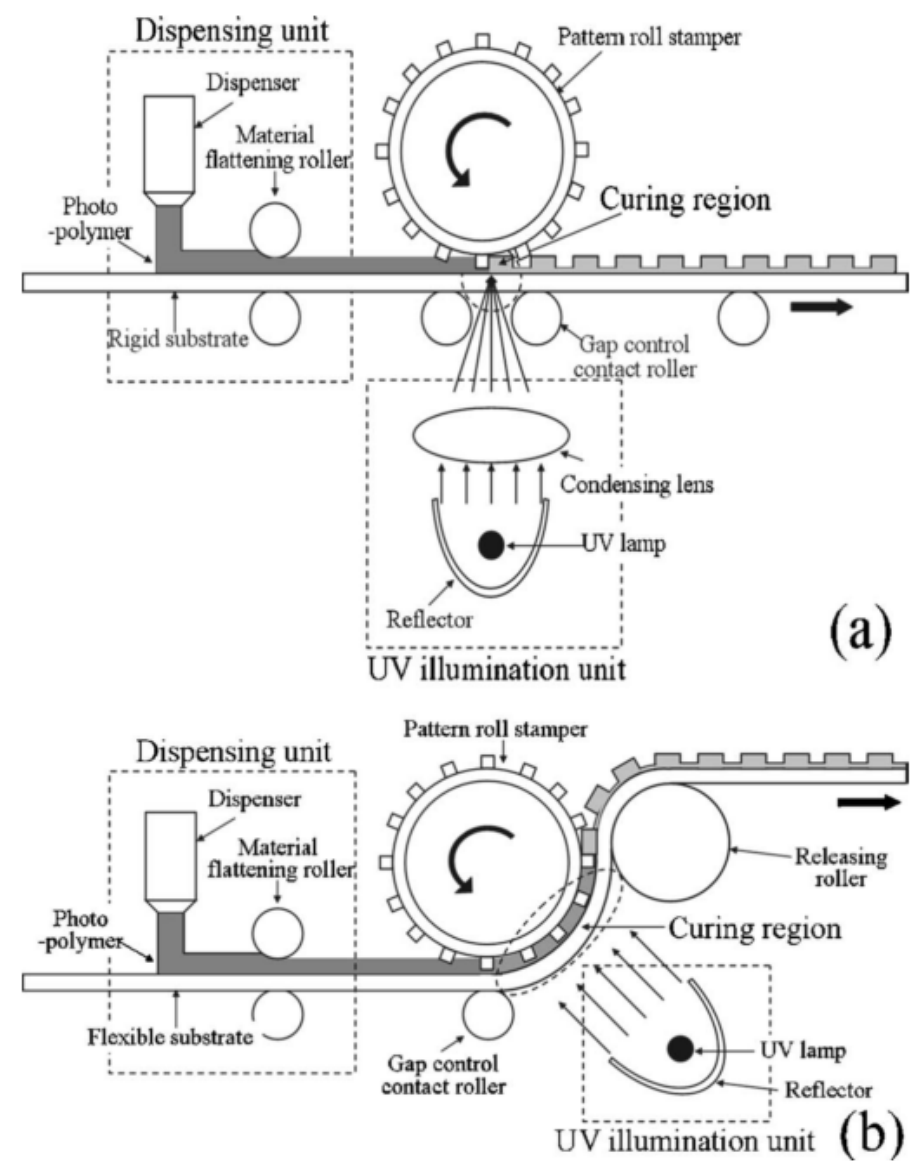

Fig.7 Schematic diagrams of the UV roll nanoimprinting system: (a) for a rigid substrate and (b) for a flexible substrate developed by Ahn et al. [33] (Reprinted from ref. [33] with permission)

\subsubsection{Advances in UV NIL}

The roll-type UVNIL process has been proposed by Lee et al.[34]. In this method, a flexible transparent thin stamp is used for the imprinting process on Si as well as on plastic substrates. The flexible PDMS (polydimethylsiloxane), polycarobontate and polyester (PET) film have been fabricated from $\mathrm{Ni}$ master stamp using thermal imprinting process. These fabricated stamps are set up on quartz cylinder and replicated on Si using the roll typed UV NIL process. 100-300 nm DVD patterns and $75 \mathrm{~nm}$ line-width patterns have been achieved using this 
process[34]. Later, Ahn and Guo [35] have demonstrated a high-speed (7.94 mm/s) and largearea (4 inch wide) roll-to-roll (RTR) and roll-to-plate (RTP) NIL apparatus to continuously imprint grating patterns with $300 \mathrm{~nm}$ linewidth. In addition to greatly improving the throughput, the apparatus has the ability to maintain the pressure uniformity and successfully de-mold in large-area imprinting, which are big challenges faced by conventional NIL. Moro et al. [36] have transferred the antireflection (AR) structure onto a polymer film by RTR UV nanoimprint lithography. As a result, the high-performance AR film with the $0.1 \%$ reflectivity and about $95 \%$ transmittance at visible wavelengths has been produced at a feed rate of $1.8 \mathrm{~m} / \mathrm{min}$. In general, it is difficult to transfer structure having high aspect ratio using RTR method. The Japanese research group, Hiroshi et al., have developed a technique based on RTR UV process to overcome this problem. A tough replica mold has been used in the RTR UV NIL process to fabricate high aspect ratio $(A R=5)$ line-and-space $(L \& S)$ pattern [37]. The L\&S pattern (height $=500 \mathrm{~nm}$, width $=100 \mathrm{~nm}$ ) was imprinted on a polyester film. One of the challenges in nanoimprinting technique is the use of a master mold. Even though NIL is a cost effective method, the cost of manufacturing a master mold is relatively higher, because it is usually fabricated by other expensive fabrication techniques such as, EBL, RIE, deep-UV lithography, chemical etching, etc. A quick solution for this problem is to manufacture the mold using a NIL method. In fact, many groups have demonstrated to use NIL for the fabrication of molds. Jarrett et al. [38] have demonstrated a technique to use RTR UV process to fabricate resin mold. The mold has been subsequently used as a master mold in a thermal nanoimprinting system.

UV NIL process can be realized at room temperature, and the required mechanical force for imprinting is smaller than thermal NIL because the mold is normally controlled at a constant distance from the substrate, on which liquid film or droplets are coated. By using RTR method, UV NIL process can increase the imprinting speed and ease the demolding process. 
Similar to thermal NIL, local shrinkage is an unsolved problem for UV NIL due to the reorientation of polymer chains during curing.

\subsection{Laser-assisted direct imprint (LADI)}

\subsubsection{Machining mechanism of LADI}

A rapid imprint technique which is named as laser-assisted direct imprint (LADI) was introduced by Chou et al. in 2002 [39]. Fig.8 shows the schematic of the LADI processing. Firstly, a single excimer laser pulse that passes through a quartz mould is adopted to melt the surface layer of silicon substrate. The solid-state silicon will be in liquid phase after absorbing the laser energy. Then, the molten silicon layer is embossed by the quartz mould. The nanoscale patterns with sub-10 nm resolution on the silicon wafer could be imprinted within the $250 \mathrm{~ns}$ embossing time. LADI is a promising approach of NIL as it can be applied to more materials (polysilicon, Ge, and dielectrics) and larger samples (more than four inches diameter or one inch square) [39]. However, precisely controlling the pressure between the quartz mould and silicon wafer must be estimated for different features of different area.

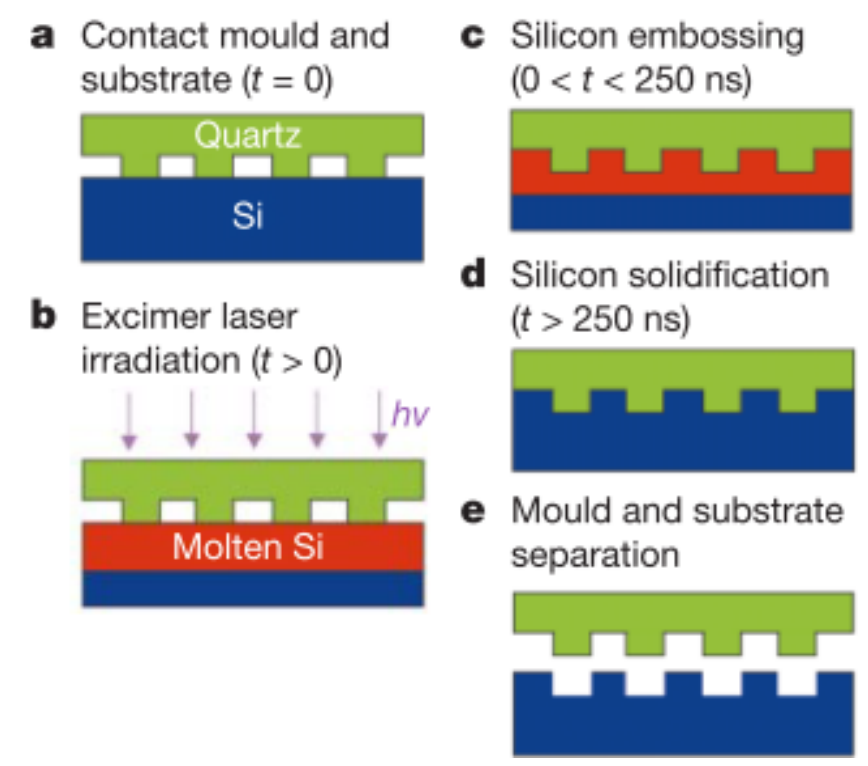

Fig.8 Schematic of LADI of nanostructures in silicon [39]. (a) A contact is made on the Si substrate with a quartz mould, (b) an excimer laser pulse is used to melt the upper layer of $\mathrm{Si}$, 
(c) embossing on $\mathrm{Si}$ is done, (d) the Si solidifies instantly retaining the patterns, (e) the mould is detached finally. (Reprinted from ref. [39] with permission)

\subsubsection{Components of LADI}

A typical laser-assisted direct imprint system mainly includes the following four parts:

- Laser source ( for example, an excimer laser pulse of $308 \mathrm{~nm}$ wavelength and $20 \mathrm{~ns}$ pulse duration [39]);

- A mould with patterns such as quartz which does not absorb the laser energy, or some metal which has to possess a higher stiffness and strength than the workpiece;

- Substrate which has a lower melting point than mould;

- A precise pressure control system between mould and substrate.

\subsubsection{Advances in LADI}

Xia et al. [40] have used the laser-assisted nanoimprint (LAN) lithography to pattern nanostructures on various polymers within a short heating and imprinting time. The result showed that the $200 \mathrm{~nm}$ pitch gratings with line width of $100 \mathrm{~nm}$ and height of $90 \mathrm{~nm}$ could be achieved with high fidelity. An approach to generate the high aspect ratio metal nanotips by means of nanosecond pulse laser melting was developed by Cui et al.[41]. As shown in Fig.9, an excimer laser pulse shines through the quartz wafer on which a thin chromium $(\mathrm{Cr})$ film is evaporated. The Cr film becomes melted and can self-form discrete metal pillars toward the top of the lower wafer due to the attractive electrostatic force. After $\mathrm{Cr}$ solidification and separation, the nanotips would be achieved both on the quartz wafer and $\mathrm{Si} / \mathrm{SiO}_{2}$ substrate. The nanotips with diameter of $10 \mathrm{~nm}$ and height of $180 \mathrm{~nm}$ could be created by using nanosecond pulse laser melting. However, it may be difficult to control the shape evolution of molten metal apex and the uniformity of nanotips array also needs to be improved. Cui et al. [42] pointed out that metallic gratings with $100 \mathrm{~nm}$ linewidth, $100 \mathrm{~nm}$ depth and $200 \mathrm{~nm}$ pitch could be imprinted even the temperature was higher than the melting 
point of the quartz mold by using LADI. Therefore, LADI is a good tool to pattern the nanostructures directly without etching, especially for metallic materials. This novel method can swiftly overcome the patterning problem on hard solid-state metal materials.

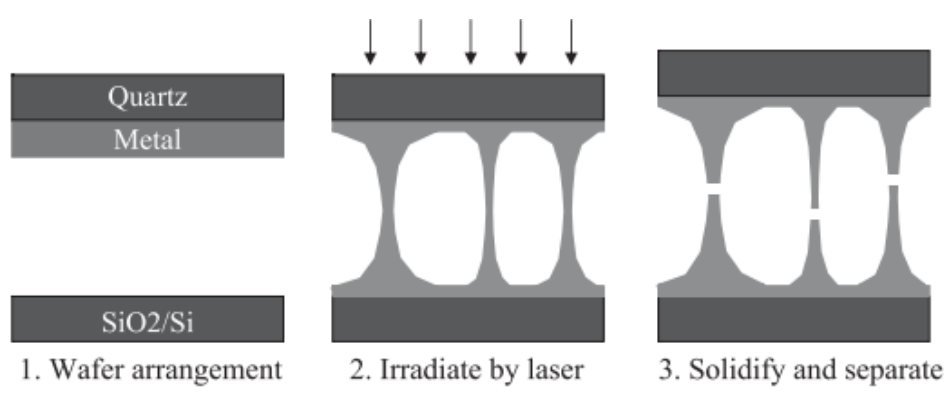

(a)

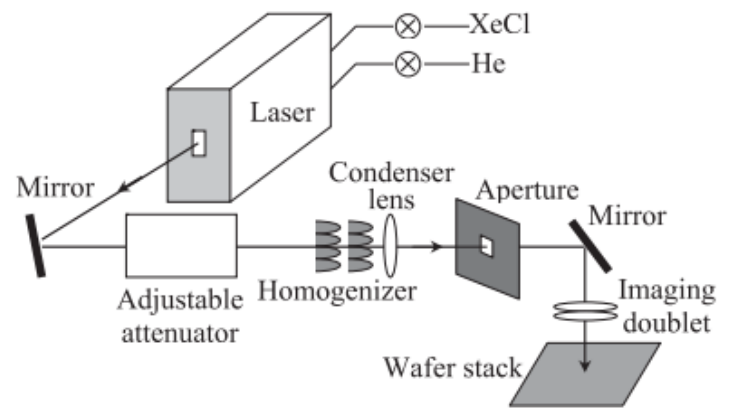

(b)

Fig.9 (a) Schematic laser-induced metal nanotip formation process; (b) schematic set-up of the excimer laser and optical components [41] ((Reprinted from ref. [41] with permission) Lee et al. [43] have developed a laser-assisted high-speed $(200 \mathrm{~mm} / \mathrm{s})$ one-step direct nanoimprinting technique for semiconductor and metal nanoparticles (NPs). As direct imprinting using NP solutions can eliminate the processes of etching, lift-off and long cooling steps, this approach can reduce the imprinting time and improve the throughput. Ehrhardt et al. [44] have used laser embossing to pattern sub-micrometer-scaled gratings into solid copper samples, and the analysis results obtained from transmission electron microscopy (TEM) and electron backscatter diffraction (EBSD) studies show that there are no significant structural modifications of monocrystalline copper. However, the effect of the residual stress on the patterned surface induced by the laser embossing process cannot be negligible. Nagato et al. [45] have proposed a laser-scanning replication on PMMA film by spot irradiation. The 
diamond-like carbon (DLC) is chosen as the light-absorption layer, which is directly irradiated and heated by a laser through the quartz. The high power density and high scanning speed of the laser lead to a high throughput. In additon, the thermal conduction_is considered to be the most important factor which limits the scanning rate. Ye and Cheng [46] have demonstrated a scaleable patterning approach on NiTi shape memory alloy by laser shock assisted direct imprinting (LSADI). A high energy pulsed laser beamshots onto the copper grid through the BK7 glass, which can induce the ionizationon on the top surface of the copper grid and thus plasma is generated. The plasma creates a shock pressure [47], which pushes the copper grid into the NiTi substrate. The obvious advantage_of LSADI is that any heating or etching process is not required to pattern metals.

LADI introduced by Chou et al is an exciting nanoimprinting approach. Compared with photolithography, the imprinting equipment of LADI is much cheaper than photolithography device because there is no need for expensive focusing optics. LADI is realized by using laser illumination and mechanical imprinting. At the moment, the resolution of photolithography is limited around $100 \mathrm{~nm}$ and it is very difficult to achieve smaller structures [48]. Compared with imprinting in a thin resist film, the LADI approach is able to pattern silicon or metals directly with sub-10 $\mathrm{nm}$ resolution and there is no need for etching process. Thus, it is likely that in the future LADI may take over costly optical lithography for silicon chips.

\subsection{Nanoelectrode lithography (NEL)}

Energetic focused electron beam can be used to fabricate nanostructures on polymer materials. This fabrication technique has been popularly known as (EBL) $[49,50]$. In EBL, a chemical reaction is initiated on the sample using the E-beam. In EBL systems, an electron gun is normally used to generate electron beam. In 1992, Majumdar et al. have used the underlying concept of EBL in an AFM system where he used the AFM tip as an electron source for 
creating nanostructure. Line pattern of $68 \mathrm{~nm}$ periodicity and $35 \mathrm{~nm}$ linewidth were successfully fabricated on PMMA samples [8].

\subsubsection{Machining mechanism of NEL}

Yokoo $[51,52]$ has conceived the idea to use nanoelectrodes for nanostructure fabrication which is called as NEL. The principle of NEL is to use a patterned nanoelectrode to induce an electrochemical reaction on the target surface. Hence, a conductive mold with patterns is needed in NEL. As shown in Fig. 10, the conductive mold is firstly controlled to contact with the target, and only the projecting part of mold can touch the top surface of the target. As it defines, a voltage is applied and current flow occurs between the mold and the target. The projecting part of the mold is the conductive area in which an electrochemical reaction is induced. As a result, the reacted part on the target will possess the patterns transferred from the conductive mold. Finally, the target is developed or etched to achieve the nanostructures like the conventional NIL. The target material can be varied. If the Si substrate is chosen, $\mathrm{SiO}_{2}$ patterns will be produced after the anodic oxidation which can be etched with $\mathrm{HF}$ solution. The $\mathrm{SiO}_{2}$ patterns with pitch of $500 \mathrm{~nm}$ and thickness of over $5 \mathrm{~nm}$ was successfully generated in a uniform area of over $400 \times 300 \mu \mathrm{m}^{2}$ by using NEL [51].

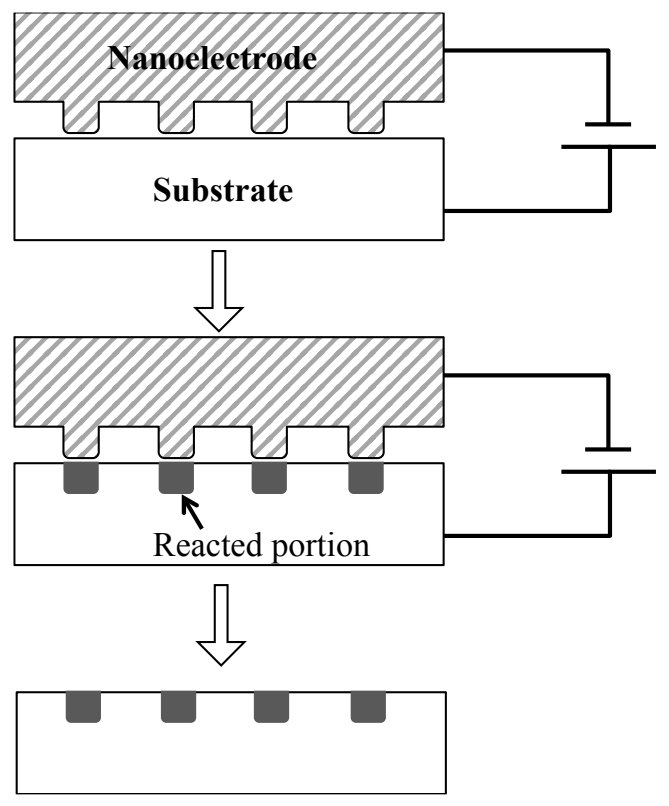

Fig.10 Principle of NEL [51] 


\subsubsection{Components of NEL}

A typical NEL system mainly includes the following parts:

- A patterned nanoelectrode which consists of a conductive area and an insulating area such as a conductive substrate with projections on its surface;

- Target substrate ( $\mathrm{Si}$, organic material, GaAs, anodic oxidation of semiconductor or metal);

- Current source ( voltage of 15-25 V and current of $2 \mathrm{~A}[51]$ );

- A mold pressure adjustment system to control the pressure oin each part of the mold;

- A constant temperature-humidity controller to manage the reaction environment and a highly accurate positioning stage;

- A development or etching process is required.

\subsubsection{Advances in NEL}

As a flexible patterning technique, the NEL can be employed repeatedly to modify the patterns. It enables multiple patterning to overwrite a patterned target [52]. Fig.11 shows the procedure of multiple patterning by NEL. In the first procedure, the electrochemical reaction on the target surface is induced by a line-and-space-pattern nanoelectrode. Second, the nanoelectrode is rotated by $90^{\circ}$ and the process is repeated to obtain a checked pattern. Multiple patterning can also be used on GaAs substrate [53]. A fabricated pattern of $400 \mathrm{~nm}$ pitch has been successfully generated on a $6 \times 8 \mathrm{~mm}^{2}$ GaAs surface within 30 s of reaction time, which can be directly used as a wet- or dry- etching mask. It is found that the pattern on the flat mold could also be transferred to a target Si substrate [54]. The flat mold includes two parts: conductive area and insulating area, which has a similar function with the master mold in NEL. Hence, the relief pattern on the mold is not necessary, so this approach can simplify the mold fabrication and modification processes. 
The development of newly emerging NEL has increased the diversity of nanofabrication techniques. NEL is not only a reasonable nanopatterning technique, but also a good choice of mold manufacturing[55]. Multiple patternings can be performed on a patterned target surface because the electrochemical reaction does not need mechanical force and will not cause any residual stress on a patterned surface. A significant issue to be improved is the reaction time which has limited the productivity of NEL. If the reaction time is decreased to meet the requirement of RTR processing, the combination of RTR process and NEL will offer superior performance in throughput in nanofabrication.

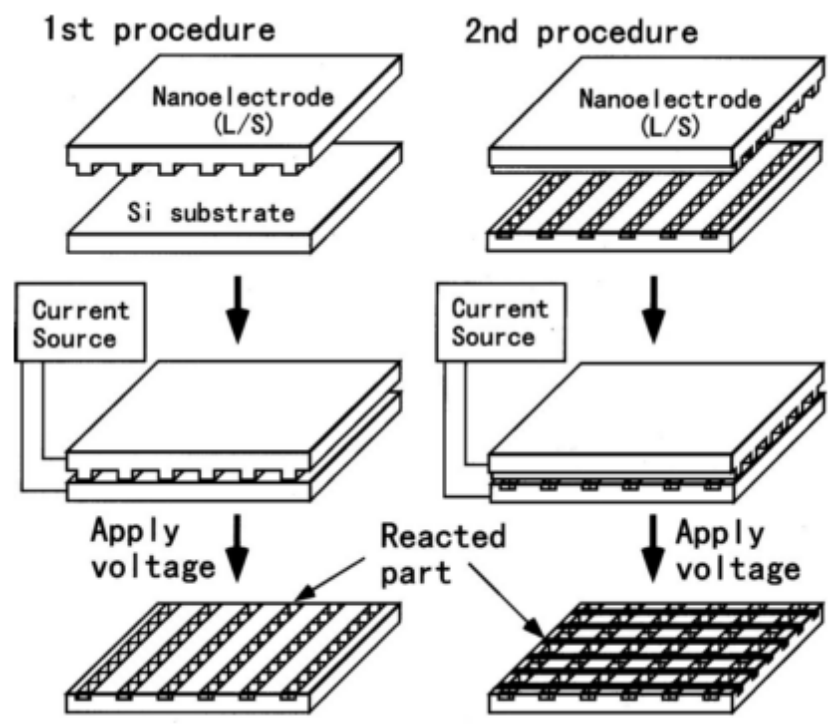

Fig.11 Experimental procedure for multiple patterning by NEL [52] (Reprinted from ref. [52] with permission)

\section{Applications of NIL}

Nanopatterns (for example, nanoholes, nanotips, nanolines and nanogrids ) have been recognised as the essential components in various fields of solar cells, optoelectronic devices, nanoscale sensors and actuators, high density magnetic disks, biological devices, micro fluidics etc. in the future manufacturing. Currently, NIL technology is one of the most successful technologies that are being used commercially for the fabrication of structures at the nanoscale. Due to its economic aspect and mass fabrication capability, NIL technique has 
been explored continuously to fabricate devices at both academic and commercial platform. Some of the successful applications of NIL in commercial products are discussed below.

\subsection{Optoelectronic devices}

Light-emitting diode (LED) in the current era has come out as one of the most efficient energy saving electric appliance. Its efficiency depends upon the accuracy of the nanostructures in it. NIL has been used to fabricate highly efficient nanostructures of varieties shapes to meet the designed efficiency specification of LED [56, 57]. An ideal miniaturized laser light sources at $385 \mathrm{~nm}$, with an emission linewidth less than $0.3 \mathrm{~nm}$ is achieved when the semiconductor nanowires is under optical excitation [58]. $\mathrm{ZnO}$ is one of the highefficiency phosphor materials, even at a low-voltage excitation. $\mathrm{ZnO}$ nanostructures open the widely applications in the fields of light-emitting display $[59,60]$, and optoelectronic devices [61]. Plasmonic Bragg mirrors with the nanohole arrays are utilized as sub-micron resolution surface plasmon resonance (SPR) imaging pixels to enhance the resolution, scalability and isolation [3]. Since NIL is a cost effective and mass fabrication technique, NIL can meet all the prerequisites to be used for the fabrication of LED devices.

\subsection{Solar cells}

Solar energy is regarded as one of the most important renewable energy sources in the future. Although it has been extensively studied for many years, cost effective manufacturing with high efficiency remains a bottle neck in utilizing solar energy. Since the birth of NIL, various groups have been using NIL for patterning nanostructures to be used for solar cells $[62,63]$. Ultrathin crystalline silicon solar cells can offer high energy conversion efficiencies, but they face a big challenge of reduced optical absorption in the red and near-infrared spectrum regions [64]. Nanoscale interface in an organic solar cell or periodic photonic nanostructures on thin-film c-Si solar cells are reported to enhance light trapping capabilities and thus improve the power conversion efficiency [64-66]. 


\subsection{Memory devices}

One of the finest uses of NIL is in magnetic devices. Such devices in general should have single-domain magnetic structure, high density patterned magnetic media. NIL has been used by various researchers to pattern magnetic nanostructure and investigate the efficiency. For example, Lee et al. have fabricated $60 \mathrm{~nm} \mathrm{Ge}_{2} \mathrm{Sb}_{2} \mathrm{Te}_{5}$ nanostructures in order to design a PRAM (Phase-change Random Access Memory) device [67]. UV NIL has been adapted by Yang et al. to pattern the PRAM in nanoscale [68]. Meier et al. have successfully used NIL technique to understand the capacity of next generation memory and logic devices [69]. Currently, commercial companies are on their way to employ NIL technique for the development of next generation semiconductor lithography system which can be used to fabricate memory devices.

\subsection{Nanoscale sensors}

NIL can produce stable and large-area nanostructures with high throughput. This technology is widely applied in the fabrication of sensor chips, biochemical sensors and waveguide sensors [70-72]. The nanoimprinting technique is able to improve the throughput with lowcost, and enhance the uniformity and sensitivity of the sensors. Moreover, during the nanoimprinting process, the fine adjustment of sensor structures can be achieved by controlling the imprinting conditions [72].

\subsection{Hydrophobic surfaces}

The functional surfaces with hydrophobicity which are characterized by the 'lotus effect' have attracted many researchers' attention, because the hydrophobic surfaces can exhibit unique properties such as self-cleaning, anti-fogging and drag reduction. UV NIL is an effective tool for mass-producible replication of highly hydrophobic surfaces from plant leaves [73]. The nano-scaled structures of superhydrophobic surfaces have been well reproduced and the contact angle has been increased noticeably using UV NIL[74]. In 
addition, the fully-covering hierarchical surface with micro/nanostructures which turn the surface into a super-hydrophobicity is achieved by NIL and modified laser swelling [75].

\subsection{Biology application}

Biological microarrays such as genomics, proteomics and tissues are essential tools to broaden the understanding of surface-mediated biological behaviours [5]. These biological microarrays have opened the wide application in the field of biosensors, biochips, tissue engineering, and bioassays [76-79]. The ability to precisely immobilize the tiny objects in well-defined patterns has been a significant challenge [80]. NIL is a parallel patterning method to fabricate biological microarrays which will increase the sensitivity and accuracy of the bio-tech devices. It is advantageous in terms of its high throughput, flexibility and simplification and low cost compared with photolithography technique. Capillary electrophoresis chips for DNA separation and nanoelectrochemical transducers for biochemical sensor is achieved using NIL [81, 82]. Moreover, NIL and molecular self-assembly have been combined to generate the protein nanopatterns [83].

\section{Challenges and the future of NIL}

\subsection{Comparison of current NIL techniques}

Table 1 shows the comparison of current NIL techniques. Thermal NIL and UV NIL can achieve a two-dimensional (2D) or two and a half-dimensional (2.5D) nanoimprint processing. Large-area RTP or RTR thermal NIL and UV NIL is a kind of continuous nanoimprinting method, which offers a superb high-throughput, short imprint time and low cost. Hence, these two techniques are widely used to fabricate nanostructures for commercial production. LADI is a physical nanoimprint process and it offers high resolution, short heating and imprinting time, no need of etching process. 2D nanopatterns with sub-10 nm resolution can be fabricated by using LADI. The power uniformity of the large-diameter laser beam is a big limitation for LADI to process the larger samples. Compared with the 
conventional NIL, NEL is categorized as a chemical nanoimprint process, and this approach offers many merits. Firstly, there are no defective patterns caused by mold release because no resist is needed in patterning process. In addition, NEL can be used to produce the flat mold, which eliminates the etching process in mold manufacturing and reduces the costs. Finally, NEL does not deform the target surface during the patterning process and there is no residual stress on the target surface. Hence, multiple patterning for complex nanostructures can be realised by using NEL or combine it with other patterning methods such as EB lithography, SPM lithography. However, the influence of the current and power-on time on the features of anodic oxidation remains unclear. The pattern resolution and uniformity by NEL should be further improved.

Table 1 Comparison of current NIL techniques

\begin{tabular}{|c|c|c|c|c|}
\hline Items & Thermal NIL & UV NIL & LADI & NEL \\
\hline Principle & $\begin{array}{l}\text { Physical } \\
\text { process }\end{array}$ & $\begin{array}{l}\text { Physical and } \\
\text { chemical process }\end{array}$ & Physical process & Chemical process \\
\hline $\begin{array}{l}\text { Machining } \\
\text { capability }\end{array}$ & $2 \mathrm{D}, 2.5 \mathrm{D}$ & $2 \mathrm{D}, 2.5 \mathrm{D}$ & $2 \mathrm{D}, 2.5 \mathrm{D}$ & $2 \mathrm{D}$ \\
\hline Resolution & $\begin{array}{l}\text { Width of } 70 \mathrm{~nm} \\
\text { and depth of } 40 \\
\mathrm{~nm}[28] ; \\
\text { Width of } 0.8- \\
5 \mu \mathrm{m} \text { and depth } \\
\text { of } 1 \mu \mathrm{m} \text { [32]. }\end{array}$ & $\begin{array}{l}\text { Pitch of } 150 \mathrm{~nm} \\
\text { and height of } 35 \\
\mathrm{~nm}[33] ; \\
\text { Pitch of } 101 \pm 5 \\
\mathrm{~nm} \text { and height of } \\
274 \pm 3 \mathrm{~nm}[36] .\end{array}$ & $\begin{array}{l}\text { Width of } 10 \mathrm{~nm} \text { and } \\
\text { depth of } 15 \mathrm{~nm} \mathrm{[39];} \\
\text { Width of } 100 \mathrm{~nm} \text { and } \\
\text { depth of } 100 \mathrm{~nm} \text { [42]; } \\
500 \mathrm{~nm} \text { [45]. }\end{array}$ & $\begin{array}{l}\text { Pitch of } 500 \mathrm{~nm} \text { and } \\
\text { depth of } 240 \mathrm{~nm}[51] \text {; } \\
\text { Pitch of } 500 \mathrm{~nm} \text { and } \\
\text { depth of } 70 \mathrm{~nm} \text { [53]; } \\
\text { Width } 300 \mathrm{~nm} \text { and depth } \\
\text { of } 20 \mathrm{~nm}[54] \text {. }\end{array}$ \\
\hline Size of sample & $\begin{array}{l}\text { Width of } 0.25-2 \\
\mathrm{~cm}[28] ; \\
100 \mathrm{~mm} \times 100 \\
\mathrm{~mm}[32] .\end{array}$ & $\begin{array}{l}80 \quad \mathrm{~mm} \text { width } \\
{[33] ;} \\
4 \mathrm{~cm}^{2}[36] .\end{array}$ & $\begin{array}{l}1.5 \mathrm{~mm} \times 1.5 \mathrm{~mm}[39] \\
1 \mathrm{~mm}^{2}[42] ; \\
10 \mathrm{~mm} \times 10 \mathrm{~mm}[45]\end{array}$ & $\begin{array}{l}400 \times 300 \mu \mathrm{m}^{2}[51] \\
6 \times 8 \mathrm{~mm}^{2}[53] .\end{array}$ \\
\hline $\begin{array}{l}\text { Imprinting speed } \\
\text { / Imprinting time }\end{array}$ & $\begin{array}{l}0.5 \text { to } 1.5 \\
\mathrm{~cm} / \mathrm{min} \quad[28] ; \\
0.1-10 \mathrm{~mm} / \mathrm{s} \\
{[32]}\end{array}$ & $\begin{array}{l}13 \mathrm{~mm} / \mathrm{s} \mathrm{[33];} \\
1.8 \mathrm{~m} / \mathrm{min}[36] .\end{array}$ & $\begin{array}{l}\text { Hundreds of } \\
\text { nanoseconds }[39,42]\end{array}$ & $\begin{array}{l}15 \text { to } 60 \text { minutes [51]; } \\
30 \mathrm{~s}[53] \text {; } \\
20 \text { minutes }[54] .\end{array}$ \\
\hline $\begin{array}{l}\text { Machinable } \\
\text { materials }\end{array}$ & Polymer & Photopolymer & $\begin{array}{l}\text { Silicon, metal, } \\
\text { polymer, } \\
\text { semiconductors, } \\
\text { dielectrics }\end{array}$ & $\begin{array}{l}\mathrm{Si} \text {, organic material, } \\
\mathrm{GaAs} \text {, anodic oxidation } \\
\text { of semiconductor or } \\
\text { metal }\end{array}$ \\
\hline Etching & No need & No need & No need & Need \\
\hline $\begin{array}{l}\text { Defective } \\
\text { patterns caused } \\
\text { by mold release }\end{array}$ & Yes & Yes & Yes & No \\
\hline
\end{tabular}




\subsection{Challenges and the future of NIL}

Soon after the invention of NIL as a simple and economical nanofabrication method, NIL was able to draw attention from researchers and engineers and quickly became a popular commercial nanofabrication tool. The reason behind the success of NIL is that NIL is a costeffective and fast nanofabrication method. However, despite of its commercial success, NIL has several issues, which need to be addressed and resolved in order to fulfil the demand of the dynamic market.

Thermal NIL is a physical nanoimprinting process and UV NIL is a physical and chemical nanoimprinting process. They are both very efficient in nanofabrication on polymer materials and can provide high-resolution structures. The fracture defect generated during demolding process and surface residual stress of the polymer substrates are unavoidable problems in thermal NIL. UV NIL is expected to have the ability to pattern more kinds of materials in addition to the UV-curable resin. LADI is also a physical nanoimprinting process and can be very useful to fabricate nanostructures on silicon, polymer, metals and semimetals. However, the power uniformity of the laser beam (having a large diameter) has been a big limitation in processing bigger samples. NEL is categorized as a chemical nanoimprinting process, and this approach offers many advantages to NEL. Nevertheless, NEL is a time-consuming process. It is because of the fact that NEL takes finite amount of time in order to complete the chemical process. Thus, if the reaction time can be reduced, NEL can eventually replace conventional EBL technique. Provided the reaction time is reduced down to few seconds or even lower than this, RTR NEL can be designed to fabricate nanostructures with higher resolution and throughput. Hence, the influences of the current and power-on time on the features have to be studied deeply. The formability mechanism in NIL process is still not fully understood, and the effect of the imprinting parameters such as temperature, loading

force, aspect ratio and imprinting velocity on formability requires a 
thorough and systematic study. To make up for the inconsistency and turbulence of experimental research, molecular dynamics (MD) simulation is an effective tool for studying material behaviour and thermodynamic properties at the atomic level[84]. In addition, the attainable resolution and the uniformity of patterns should be improved.

One of the disadvantages of NIL over other nanofabrication techniques is the flexibility of patterning. For example, if the designed pattern is changed slightly, the mold has to be remanufactured. NIL has been very successful in nanopatterning regular shapes. However, NIL might not be a suitable tool in fabrication of complex structures. Integrating NIL with other existing nanofabrication techniques can be helpful in order to overcome such issues. Each existing nanofabrication methodology has its advantages and imperfections. The key is to find a stage and provide full play to the advantages of different nanotechnologies, which consist of EBL, AFM lithography, SPM lithography, Focused Ion Beam (FIB), optical lithography, NIL, molecular self-assembly, etc [85-87]. The integrated use of the physical and chemical nanopatterning approaches is highly anticipated to improve the pattern resolution, uniformity and throughput, as well as to fabricate desired 3D nanostructures.

In the past decades, the semiconductor and circuitry industries have witnessed the rapid development of nanoimprint lithography, whilst research on NIL in biological application is limited and worthy of an in-depth study in the future. The development of biochips, artificial organs, diagnostic system, and fundamental research in cell biology will be benefited from fabricating protein arrays at a molecular level. These potential applications will attract researchers to push nanoimprint lithography forward at a resolution of $10 \mathrm{~nm}$ or less in the future.

\section{Concluding Remarks}

Despite of the late invention of nanoimprinting technique, NIL has quickly broken through the barrier of laboratory fabrication scale to industrial production and become one of the most 
employed commercial platform for nanofabrication. The reasons are the simplicity it adopts, the resolution of the structures it can offer, high throughput and the cost-effectiveness involved in the fabrication approaches.

Through this article, an overall view of the major commercially successful NIL techniques (Thermal and UV) along with the still-in-laboratory but promising (LADI and NEL) NIL techniques has been provided. The machining mechanism, components and advances of each method have been discussed in order to provide a clear understanding of the techniques. Moreover the methods have been compared in terms of machining capability, speed, sample materials and size, resolution of the fabricated structures, etc. Through this direct comparison, readers can quickly access to the advantages and limitations of each technique.

Despite of the huge commercial success, there are still many challenges which lie in NIL fabrication processes and some of the key points have been discussed in this article. Possible solutions to those challenges have been discussed in order to provide a multi-directional approach for the researchers to think and pursue on the issues.

\section{Acknowledgment}

The authors gratefully acknowledge the financial supports of EPSRC (EP/K018345/1) and Royal Society-NSFC international exchange program for this work.

\section{References}

1. Guo, L.J.: Nanoimprint lithography: Methods and material requirements. Advanced Materials. 19, 495-513 (2007).

2. Austin, M.D., Chou, S.Y.: Fabrication of a Molecular Self-Assembled Monolayer Diode Using Nanoimprint Lithography. Nano Letters. 3, 1687-1690 (2003).

3. Lindquist, N.C., Lesuffleur, A., Im, H., Oh, S.-H.: Sub-micron resolution surface plasmon resonance imaging enabled by nanohole arrays with surrounding Bragg mirrors for enhanced sensitivity and isolation. Lab on a chip. 9, 382-387 (2009). 
4. Chou, S.Y., Wei, M.S., Krauss, P.R., Fischer, P.B.: Single-domain magnetic pillar array of $35 \mathrm{~nm}$ diameter and 65 Gbits/in. 2 density for ultrahigh density quantum magnetic storage. Journal of Applied Physics. 76, 6673-6675 (1994).

5. $\quad$ Truskett, V.N., Watts, M.P.C.: Trends in imprint lithography for biological applications. Trends in Biotechnology. 24, 312-317 (2006).

6. Ito, T., Okazaki, S.: Pushing the limits of lithography. Nature. 406, 1027-31 (2000).

7. Snow, E.S., Campbell, P.M., McMarr, P.J.: Fabrication of silicon nanostructures with a scanning tunneling microscope. Applied Physics Letters. 63, 749-751 (1993).

8. Majumdar, a., Oden, P.I., Carrejo, J.P., Nagahara, L. a., Graham, J.J., Alexander, J.: Nanometer-scale lithography using the atomic force microscope. Applied Physics Letters. 61, 2293-2295 (1992).

9. Luo, G., Xie, G., Zhang, Y., Zhang, G., Zhang, Y., Carlberg, P., Zhu, T., Liu, Z.: Scanning probe lithography for nanoimprinting mould fabrication. Nanotechnology. 17, 3018-3022 (2006).

10. Chou, S.Y., Krauss, P.R., Renstrom, P.J.: Imprint Lithography with 25-Nanometer Resolution. Science. 272, 85-87 (1996).

11. Chou, S.Y.: Nanoimprint lithography. Journal of Vacuum Science \& Technology B: Microelectronics and Nanometer Structures. 14, 4129 (1996).

12. Schift, H.: Nanoimprint lithography: An old story in modern times? A review. Journal of Vacuum Science \& Technology B: Microelectronics and Nanometer Structures. 26, 458 (2008).

13. Hua, F., Sun, Y., Gaur, A., Meitl, M. a., Bilhaut, L., Rotkina, L., Wang, J., Geil, P., Shim, M., Rogers, J. a., Shim, A.: Polymer imprint lithography with molecular-scale resolution. Nano Letters. 4, 2467-2471 (2004).

14. Lebib, a., Chen, Y., Bourneix, J., Carcenac, F., Cambril, E., Couraud, L., Launois, H.: Nanoimprint lithography for a large area pattern replication. Microelectronic Engineering. 46, 319-322 (1999).

15. Ahn, S.-W., Lee, K.-D., Kim, J.-S., Kim, S.H., Park, J.-D., Lee, S.-H., Yoon, P.-W.: Fabrication of a $50 \mathrm{~nm}$ half-pitch wire grid polarizer using nanoimprint lithography. Nanotechnology. 16, 1874-1877 (2005).

16. Malloy, M., Litt, L.C.: Technology review and assessment of nanoimprint lithography for semiconductor and patterned media manufacturing. Journal of Micro/Nanolithography, MEMS and MOEMS. 10, 032001 (2011).

17. Zhou, W., Min, G., Zhang, J., Liu, Y.: Nanoimprint Lithography : A Processing Technique for Nanofabrication Advancement. 3, 135-140 (2011).

18. Ko, D.-H., Tumbleston, J.R., Gadisa, A., Aryal, M., Liu, Y., Lopez, R., Samulski, E.T.: Light-trapping nano-structures in organic photovoltaic cells. Journal of Materials Chemistry. 21, 16293 (2011).

19. Oh, S.S., Choi, C.G., Kim, Y.S.: Fabrication of micro-lens arrays with moth-eye antireflective nanostructures using thermal imprinting process. Microelectronic Engineering. 87, 2328-2331 (2010).

20. Okada, M., Miyake, H., Iyoshi, S., Yukawa, T., Katase, T., Tone, K., Haruyama, Y., Matsui, S.: Double patterning in nanoimprint lithography. Microelectronic Engineering. 112, 139-142 (2013). 
21. Tseng, A. a., Chen, K., Chen, C.D., Ma, K.J.: Electron beam lithography in nanoscale fabrication: Recent development. IEEE Transactions on Electronics Packaging Manufacturing. 26, 141-149 (2003).

22. Kricka, L.J., Fortina, P., Panaro, N.J., Wilding, P., Alonso-Amigo, G., Becker, H.: Fabrication of plastic microchips by hot embossing. Lab on a chip. 2, 1-4 (2002).

23. Belligundu, S., Shiakolas, P.S.: Study on two-stage hot embossing microreplication: silicon to polymer to polymer. Journal of Microlithography, Microfabrication, and Microsystems. 5, 021103 (2006).

24. Jaszewski, R.W., Schift, H., Schnyder, B., Schneuwly, a., Gröning, P.: Deposition of anti-adhesive ultra-thin teflon-like films and their interaction with polymers during hot embossing. Applied Surface Science. 143, 301-308 (1999).

25. Lee, G. Bin, Chen, S.H., Huang, G.R., Sung, W.C., Lin, Y.H.: Microfabricated plastic chips by hot embossing methods and their applications for DNA separation and detection. Sensors and Actuators, B: Chemical. 75, 142-148 (2001).

26. Ong, N.., Koh, Y.., Fu, Y..: Microlens array produced using hot embossing process. Microelectronic Engineering. 60, 365-379 (2002).

27. Chou, S.Y., Krauss, P.R., Renstrom, P.J.: Imprint of sub-25 nm vias and trenches in polymers. Applied Physics Letters. 67, 3114 (1995).

28. Tan, H., Gilbertson, A., Chou, S. Y.: Roller nanoimprint lithography. Journal of Vacuum Science \& Technology B: Microelectronics and Nanometer Structures. 16, 3926 (1998).

29. Hirai, Y., Yoshida, S., Takagi, N.: Defect analysis in thermal nanoimprint lithography. Journal of Vacuum Science \& Technology B: Microelectronics and Nanometer Structures. 21, 2765 (2003).

30. Bilenberg, B., Hansen, M., Johansen, D., Özkapici, V., Jeppesen, C., Szabo, P., Obieta, I.M., Arroyo, O., Tegenfeldt, J.O., Kristensen, a.: Topas-based lab-on-a-chip microsystems fabricated by thermal nanoimprint lithography. Journal of Vacuum Science \& Technology B: Microelectronics and Nanometer Structures. 23, 2944 (2005).

31. Yang, K.-Y., Yoon, K.-M., Lim, S., Lee, H.: Direct indium tin oxide patterning using thermal nanoimprint lithography for highly efficient optoelectronic devices. Journal of Vacuum Science \& Technology B: Microelectronics and Nanometer Structures. 27, 2786 (2009).

32. Youn, S.W., Ogiwara, M., Goto, H., Takahashi, M., Maeda, R.: Prototype development of a roller imprint system and its application to large area polymer replication for a microstructured optical device. Journal of Materials Processing Technology. 202, 76-85 (2008).

33. Ahn, S., Cha, J., Myung, H., Kim, S.M., Kang, S.: Continuous ultraviolet roll nanoimprinting process for replicating large-scale nano- and micropatterns. Applied Physics Letters. 89, 12-15 (2006).

34. Lee, J., Park, S., Choi, K., Kim, G.: Nano-scale patterning using the roll typed UVnanoimprint lithography tool. Microelectronic Engineering. 85, 861-865 (2008).

35. Ahn, S.H., Guo, L.J.: Large-area roll-to-roll and roll-to-plate Nanoimprint Lithography: A step toward high-throughput application of continuous nanoimprinting. ACS Nano. 3, 2304-2310 (2009). 
36. Moro, M., Taniguchi, J., Hiwasa, S.: Fabrication of antireflection structure film by roll-to-roll ultraviolet nanoimprint lithography. Journal of Vacuum Science \& Technology B, Nanotechnology and Microelectronics: Materials, Processing, Measurement, and Phenomena. 32, 06FG09 (2014).

37. Yoshikawa, H., Taniguchi, J., Tazaki, G., Zento, T.: Fabrication of high-aspect-ratio pattern via high throughput roll-to-roll ultraviolet nanoimprint lithography. Microelectronic Engineering. 112, 273-277 (2013).

38. Dumond, J.J., Mahabadi, K.A., Yee, Y.S., Tan, C., Fuh, J.Y.H., Lee, H.P., Low, H.Y.: High resolution UV roll-to-roll nanoimprinting of resin moulds and subsequent replication via thermal nanoimprint lithography. Nanotechnology. 23, 485310 (2012).

39. Chou, S.Y., Keimel, C., Gu, J.: Ultrafast and direct imprint of nanostructures in silicon. Nature. 417, 835-837 (2002).

40. Xia, Q., Keimel, C., Ge, H., Yu, Z., Wu, W., Chou, S.Y.: Ultrafast patterning of nanostructures in polymers using laser assisted nanoimprint lithography. Applied Physics Letters. 83, 4417-4419 (2003).

41. Cui, B., Wu, L., Chou, S.Y.: Fabrication of high aspect ratio metal nanotips by nanosecond pulse laser melting. Nanotechnology. 19, 345303 (2008).

42. Cui, B., Keimel, C., Chou, S.Y.: Ultrafast direct imprinting of nanostructures in metals by pulsed laser melting. Nanotechnology. 21, 045303 (2010).

43. Lee, D., Pan, H., Sherry, A., Ko, S.H., Lee, M.-T., Kim, E., Grigoropoulos, C.P.: Large-area nanoimprinting on various substrates by reconfigurable maskless laser direct writing. Nanotechnology. 23, 344012 (2012).

44. Ehrhardt, M., Lorenz, P., Lotnyk, a, Romanus, H., Thelander, E., Zimmer, K.: Pattern Transfer of Sub-micrometre-scaled Structures into Solid Copper by Laser Embossing. Physics Procedia. 56, 944-950 (2014).

45. Nagato, K., Takahashi, K., Sato, T., Choi, J., Hamaguchi, T., Nakao, M.: Laserassisted replication of large-area nanostructures. Journal of Materials Processing Technology. 214, 2444-2449 (2014).

46. Ye, C., Cheng, G.J.: Scalable patterning on shape memory alloy by laser shock assisted direct imprinting. Applied Surface Science. 258, 10042-10046 (2012).

47. Fabbro, R., Fournier, J., Ballard, P., Devaux, D., Virmont, J.: Physical study of laserproduced plasma in confined geometry. Journal of Applied Physics. 68, 775-784 (1990).

48. Pease, R.F.: Imprints offer Moore. Nature. 417, 802-803 (2002).

49. Chen, W., Ahmed, H.: Fabrication of 5-7 nm wide etched lines in silicon using 100 $\mathrm{keV}$ electron-beam lithography and polymethylmethacrylate resist. Applied Physics Letters. 62, 1499-1501 (1993).

50. Fujita, J., Ohnishi, Y., Ochiai, Y., Matsui, S.: Ultrahigh resolution of calixarene negative resist in electron beam lithography. Applied Physics Letters. 1297, 1297 (1995).

51. Yokoo, A.: Nanoelectrode lithography. Japanese Journal of Applied Physics, Part 2: Letters. 42, 92-94 (2003). 
52. Yokoo, a., Yokoo, a.: Nanoelectrode lithography and multiple patterning. Journal of Vacuum Science \& Technology B: Microelectronics and Nanometer Structures. 21, 2966 (2003).

53. Yokoo, A., Sasaki, S.: Oxidation patterning of GaAs by nanoelectrode lithography. Japanese Journal of Applied Physics, Part 1: Regular Papers and Short Notes and Review Papers. 44, 1119-1122 (2005).

54. Yokoo, A., Namatsu, H.: Nanoelectrode lithography using a flat mold with a pattern defined by different conductivities. Microelectronic Engineering. 87, 931-935 (2010).

55. Scaffaro, R., Shim, E., Hahn, H.: Reliability and Fabrication of Molds for Nanoimprinting. Current Nanoscience. 6, 1-11 (2010).

56. Lee, K.D., Kim, S.H., Park, J.D., Kim, J.Y., Park, S.J.: Application of nanoimprint lithography to nano-optics: wire grid polarizer and photonic crystal LED. Proceedings of SPIE. 6462, 64620P (2007).

57. Kim, S.H., Lee, K.-D., Kim, J.-Y., Kwon, M.-K., Park, S.-J.: Fabrication of photonic crystal structures on light emitting diodes by nanoimprint lithography. 055306, (2010).

58. Huang, M.H., Mao, S., Feick, H., Yan, H., Wu, Y., Kind, H., Weber, E., Russo, R., Yang, P.: Room-temperature ultraviolet nanowire nanolasers. Science (New York, N.Y.). 292, 1897-1899 (2001).

59. Saito, N., Haneda, H., Sekiguchi, T., Ohashi, N., Sakaguchi, I., Koumoto, K.: Lowtemperature fabrication of light-emitting zinc oxide micropatterns using self-assembled monolayers. Advanced Materials. 14, 418-420 (2002).

60. Kang, H.W., Yeo, J., Hwang, J.O., Hong, S., Lee, P., Han, S.Y., Lee, J.H., Rho, Y.S., Kim, S.O., Ko, S.H., Sung, H.J.: Simple ZnO nanowires patterned growth by microcontact printing for high performance field emission device. Journal of Physical Chemistry C. 115, 11435-11441 (2011).

61. Wang, X., Summers, C.J., Wang, Z.L.: Large-scale hexagonal-patterned growth of aligned $\mathrm{ZnO}$ nanorods for nano-optoelectronics and nanosensor arrays. Nano Letters. 4, 423-426 (2004).

62. Hauser, H., Michl, B., Schwarzkopf, S., Kübler, V., Müller, C., Hermle, M., Bläsi, B.: Honeycomb texturing of silicon via nanoimprint lithography for solar cell applications. IEEE Journal of Photovoltaics. 2, 114-122 (2012).

63. Jiao, F., Huang, Q., Ren, W., Zhou, W., Qi, F., Zheng, Y., Xie, J.: Enhanced performance for solar cells with moth-eye structure fabricated by UV nanoimprint lithography. Microelectronic Engineering. 103, 126-130 (2013).

64. Trompoukis, C., El Daif, O., Depauw, V., Gordon, I., Poortmans, J.: Photonic assisted light trapping integrated in ultrathin crystalline silicon solar cells by nanoimprint lithography. Applied Physics Letters. 101, 1-5 (2012).

65. Herman, A., Trompoukis, C., Depauw, V., El Daif, O., Deparis, O.: Influence of the pattern shape on the efficiency of front-side periodically patterned ultrathin crystalline silicon solar cells. Journal of Applied Physics. 112, (2012).

66. Feltrin, A., Meguro, T., Van Assche, E., Suezaki, T., Ichikawa, M., Kuchiyama, T., Adachi, D., Inaki, O., Yoshikawa, K., Koizumi, G., Uzu, H., Ueda, H., Uto, T., Fujimoto, T., Irie, T., Hayakawa, H., Nakanishi, N., Yoshimi, M., Yamamoto, K.: Advanced light trapping designs for high efficiency thin film silicon solar cells. Solar Energy Materials and Solar Cells. 119, 219-227 (2013). 
67. Lee, H., Hong, S.H., Yang, K.Y., Jung, G.Y.: Fabrication of Ge2Sb2Te5 based PRAM device at $60 \mathrm{~nm}$ scale by using UV nanoimprint lithography. Microelectronic Engineering. 84, 573-576 (2007).

68. Yang, K.-Y., Hong, S.-H., Kim, D., Cheong, B., Lee, H.: Patterning of Ge2Sb2Te5 phase change material using UV nano-imprint lithography. Microelectronic Engineering. 84, 21-24 (2007).

69. Meier, M., Nauenheim, C., Gilles, S., Mayer, D., Kügeler, C., Waser, R.: Nanoimprint for future non-volatile memory and logic devices. Microelectronic Engineering. 85, 870-872 (2008).

70. Nishikawa, T., Yamashita, H., Nakamura, M., Hasui, R., Matsushita, T., Aoyama, S.: Development of New Localized Surface Plasmon Resonance Sensor with Nanoimprinting Technique. 2006 1st IEEE International Conference on Nano/Micro Engineered and Molecular Systems. 262-265 (2006).

71. Chao, C.Y., Guo, L.J.: Biochemical sensors based on polymer microrings with sharp asymmetrical resonance. Applied Physics Letters. 83, 1527-1529 (2003).

72. Wan, D., Chen, H.L., Lai, Y.T., Yu, C.C., Lin, K.F.: Use of reversal nanoimprinting of nanoparticles to prepare flexible waveguide sensors exhibiting enhanced scattering of the surface plasmon resonance. Advanced Functional Materials. 20, 1742-1749 (2010).

73. Lee, S.-M., Kwon, T.H.: Mass-producible replication of highly hydrophobic surfaces from plant leaves. Nanotechnology. 17, 3189-3196 (2006).

74. Lee, S.-M., Kwon, T.H.: Effects of intrinsic hydrophobicity on wettability of polymer replicas of a superhydrophobic lotus leaf. Journal of Micromechanics and Microengineering. 17, 687-692 (2007).

75. Shao, J., Ding, Y., Wang, W., Mei, X., Zhai, H., Tian, H., Li, X., Liu, B.: Generation of fully-covering hierarchical micro-/nano- structures by nanoimprinting and modified laser swelling. Small. 10, 2595-2601 (2014).

76. Kane, R.: Patterning proteins and cells using soft lithography. Biomaterials. 20, 23632376 (1999).

77. Petrou, P.S., Chatzichristidi, M., Douvas, A.M., Argitis, P., Misiakos, K., Kakabakos, S.E.: A biomolecule friendly photolithographic process for fabrication of protein microarrays on polymeric films coated on silicon chips. Biosensors and Bioelectronics. 22, 1994-2002 (2007).

78. Kam, L., Boxer, S.: Cell adhesion to protein - micropatterned - supported lipid bilayer membranes. Journal of biomedical materials research. 55, 487-495 (2001).

79. Falconnet, D., Csucs, G., Michelle Grandin, H., Textor, M.: Surface engineering approaches to micropattern surfaces for cell-based assays. Biomaterials. 27, 30443063 (2006).

80. Hoff, J.D., Cheng, L.J., Meyhöfer, E., Guo, L.J., Hunt, A.J.: Nanoscale protein patterning by imprint lithography. Nano Letters. 4, 853-857 (2004).

81. Pépin, a., Youinou, P., Studer, V., Lebib, a., Chen, Y.: Nanoimprint lithography for the fabrication of DNA electrophoresis chips. Microelectronic Engineering. 61-62, 927-932 (2002).

82. Beck, M., Persson, F., Carlberg, P., Graczyk, M., Maximov, I., Ling, T.G.I., Montelius, L.: Nanoelectrochemical transducers for (bio-) chemical sensor applications fabricated by nanoimprint lithography. Microelectronic Engineering. 73-74, 837-842 (2004). 
83. Falconnet, D., Pasqui, D., Park, S., Eckert, R., Schift, H., Gobrecht, J., Barbucci, R., Textor, M.: A novel approach to produce protein nanopatterns by combining nanoimprint lithography and molecular self-assembly. Nano Letters. 4, 1909-1914 (2004).

84. Hsu, Q. C., Lin, Y. T., Chou, D. C., Wu, C. D.: Study on Nanoimprint Formability Considering the Anti-adhesion Layer for $(\mathrm{CH} 2)$ n Polymer by Molecular Dynamics Simulation. Current Nanoscience. 8, 424-431 (2012).

85. Chou, S.Y.: Nanoimprint Lithography and Lithographically Induced Self-Assembly. MRS Bulletin. 26, 512-517 (2001).

86. Maury, P., Escalante, M., Reinhoudt, D.N., Huskens, J.: Directed assembly of nanoparticles onto polymer-imprinted or chemically patterned templates fabricated by nanoimprint lithography. Advanced Materials. 17, 2718-2723 (2005).

87. Maune, H.T., Han, S.-P., Barish, R.D., Bockrath, M., Iii, W. a G., Rothemund, P.W.K., Winfree, E.: Self-assembly of carbon nanotubes into two-dimensional geometries using DNA origami templates. Nature nanotechnology. 5, 61-66 (2010). 